\title{
ANTI-HLA ANTIBODY BINDING TO HLA CLASS I MOLECULES INDUCES PROLIFERATION OF AIRWAY EPITHELIAL CELLS: A POTENTIAL MECHANISM FOR BRONCHIOLITIS OBLITERANS SYNDROME
}

Scott I. Reznik, MD

Andrés Jaramillo, $\mathrm{PhD}^{\mathrm{a}, \mathrm{b}}$

Leiying Zhang, $\mathrm{MD}^{\mathrm{a}}$

G. Alexander Patterson, $\mathrm{MD}^{\mathrm{a}}$

Joel D. Cooper, MDa

T. Mohanakumar, $\mathrm{PhD}^{\mathrm{a}, \mathrm{b}}$
Objective: Development of anti-HLA antibodies is associated with development of bronchiolitis obliterans syndrome after lung transplantation. We sought to determine the mechanism by which anti-HLA antibodies affect the development of bronchiolitis obliterans syndrome. We postulated that anti-HLA antibodies bind to the donor lung epithelium and stimulate phosphorylation and proliferation. Methods: The A549 lung epithelial carcinoma cell line was cultured in serum-deficient medium to produce static growth. Then the cells were treated with anti-HLA sera from lung transplant recipients, pooled anti-HLA serum from highly sensitized patients, or normal human serum. The cells were also treated with the W6/32 mouse anti-HLA class I monoclonal antibody or control mouse IgG. Tritiated thymidine uptake was determined at 24, 48, and 72 hours. In parallel experiments the cells were treated as described above, and the levels of tyrosine phosphorylation were determined by Western blot analysis. Results: Cells treated with anti-HLA serum or the W6/32 monoclonal antibody exhibited significantly greater proliferation and tyrosine phosphorylation of proteins of approximately 170, 130, 110, and $70 \mathrm{kd}$ compared with cells treated with normal human serum or mouse IgG, respectively. Conclusions: These data indicate that anti-HLA antibodies have the ability to stimulate airway epithelial cell proliferation and that they may play an important role in the development of bronchiolitis obliterans syndrome. Prevention of HLA sensitization and immunosuppression with agents capable of blocking indirect antigen presentation and the humoral immune response against the allograft may be pivotal in preventing the development of bronchiolitis obliterans syndrome after lung transplantation. (J Thorac Cardiovasc Surg 2000;119:39-45) ung transplantation has become a viable therapeutic alternative for the treatment of end-stage pulmonary disease. The obstacle to the long-term success of lung

From the Departments of Surgery ${ }^{\mathrm{a}}$ and Pathology, ${ }^{\mathrm{b}}$ Washington University School of Medicine, St Louis, Mo.

Supported by National Institutes of Health grant No. HL56643 (T. M.). S. R. is the recipient of the National Research Service Award No. HL07776. A. J. is the recipient of the National Research Service Award No. AI07163.

Read at the Seventy-ninth Annual Meeting of The American Association for Thoracic Surgery, New Orleans, La, April 18-21, 1999.

Received for publication April 22, 1999; revisions requested June 25, 1999; revisions received Aug 3, 1999; accepted for publication Sept 22, 1999.

Address for reprints: T. Mohanakumar, $\mathrm{PhD}$, Department of Surgery, Washington University School of Medicine, Box 8109-3328, CSRB, 660 South Euclid Ave, St Louis, MO 63110-1093 (E-mail: kumart@msnotes.wustl.edu).

Copyright @ 2000 by Mosby, Inc.

$0022-5223 / 2000 \$ 12.00+0 \quad \mathbf{1 2 / 6 / 1 0 3 1 4 8}$ transplantation is the development of bronchiolitis obliterans syndrome (BOS), which is the manifestation of chronic rejection. BOS has become the leading cause of late morbidity and mortality after lung transplantation. BOS is defined clinically as the progressive loss of pulmonary function in the absence of infection or acute rejection. Histologically, obliterative bronchiolitis is characterized by small airway inflammation and dense fibrosis of the lamina propria and lumen with some degree of interstitial fibrosis. ${ }^{1}$ Although the etiology of BOS is unknown and may possibly be multifactorial, most investigators agree that it is the sequelae of the recipient immune response against the lung allograft. BOS after lung transplantation was first reported in 1968 in a canine transplant model. ${ }^{2}$ One paradigm holds that the epithelium, endothelium, or both are injured by the immune response against the allograft and the subsequent repair and tissue remodeling results in BOS. ${ }^{3}$ 
Previous studies have linked the development of antiHLA antibodies with chronic rejection of both heart and renal allografts. ${ }^{4,5}$ In this regard, previous studies from our group have shown that HLA-A mismatch and the development of anti-HLA class I antibodies after lung transplantation correlate with the earlier development of BOS. ${ }^{6,7}$ A more recent multicenter retrospective study also showed that the number of HLA-DR and HLA-A mismatches independently predicted the 1year mortality rate after lung transplantation. ${ }^{8}$ In addition, the total number of HLA mismatches independently predicted 3- and 5-year mortality rates after lung transplantation. However, other clinical parameters had a stronger effect in predicting the mortality rate 5 years after lung transplantation. ${ }^{8}$

The chronic rejection of solid organ allografts appears to share similar properties. Each syndrome of rejection is characterized by a progressive deterioration of organ function with gradual fibrosis of the graft vasculature and parenchyma. The mechanism by which anti-HLA antibodies may result in the changes seen in chronic rejection in heart and renal allografts has not been elucidated. In addition, a causal relationship between the development of anti-HLA antibodies and BOS is yet to be defined. Recent studies have shown that binding of anti-HLA class I antibodies stimulates tyrosine phosphorylation and proliferation of endothelial cells. ${ }^{9,10}$ The studies described herein also show that binding of anti-HLA class I antibodies to airway epithelial cells (AECs) also induces intracellular signal transduction, which results in tyrosine phosphorylation and proliferation. The studies described herein indicate that antiHLA antibodies may contribute to the development of BOS by binding to HLA class I molecules in the lung allograft epithelium and may directly activate these cells to produce fibrogenic growth factors in situ, resulting in the typical histopathology observed in obliterative bronchiolitis.

\section{Methods}

Cells. The A549 lung epithelial carcinoma cell line was obtained from the American Type Culture Collection (Manassas, Va).

Serum samples. Pooled anti-HLA serum was obtained from 10 patients awaiting kidney transplantation with $100 \%$ reactivity against a reference panel consisting of lymphocytes from 50 unrelated individuals of known HLA antigen specificity. Anti-HLA ${ }^{+}$sera from lung transplant recipients who had BOS at the time of the study (patients 1,2, and 3) and anti-HLA ${ }^{-}$sera from patients who were free of BOS at the time of the study (patients $4,5,6$, and 7) were used. $\mathrm{AB} \mathrm{Rh^{+ }}$ normal human serum (NHS) was obtained from C-six Diagnostics (Germantown, Wis). All the lung transplant recipients included in this study were anti-HLA- before the transplant. Anti-HLA antibody reactivity was determined by standard microcytoxicity assays. All of the sera were heat inactivated at $56^{\circ} \mathrm{C}$ for 30 minutes.

Antibodies. The W6/32 mouse IgG monoclonal antibody specific for a framework determinant on the HLA class I molecule was obtained from the American Type Culture Collection. Mouse IgG, used as isotype control, was obtained from Jackson ImmunoResearch Laboratories (West Grove, $\mathrm{Pa})$.

Western blotting for phosphotyrosine. The A549 cells were grown to $75 \%$ confluence in RPMI-1640 medium (Sigma, St Louis, Mo) supplemented with $15 \%$ fetal bovine serum (Biocell Laboratories, Rancho Dominguez, Calif), 25 $\mathrm{mmol} / \mathrm{L} \quad \mathrm{N}$-[2-hydroxyethyl]piperazine-N-[2-ethanesulfonic acid], $1 \mathrm{mmol} / \mathrm{L}$ sodium pyruvate, $2 \mathrm{mmol} / \mathrm{L}$ glutamine, 10 $\mathrm{U} / \mathrm{mL}$ penicillin, and $10 \mu \mathrm{g} / \mathrm{mL}$ streptomycin (complete medium). After 24 hours, the medium was replaced with RPMI-1640 medium containing 1\% fetal bovine serum (starvation medium). After 48 hours, the cells were harvested, and $5 \times 10^{5}$ cells were placed in Eppendorf tubes. The samples were then treated for 5 and 10 minutes at $37^{\circ} \mathrm{C}$, with starvation medium containing the W6/32 monoclonal antibody (10 $\mu \mathrm{g} / \mathrm{mL})$, mouse $\operatorname{IgG}(10 \mu \mathrm{g} / \mathrm{mL})$, anti-HLA serum (1:4), or NHS (1:4). The tyrosine phosphorylation reactions were stopped by the addition of tris-hydroxymethyl-amino methane (TRIS)-buffered saline containing $5 \mu \mathrm{g} / \mathrm{mL}$ aprotinin, $10 \mu \mathrm{g} / \mathrm{mL}$ leupeptin, $10 \mu \mathrm{g} / \mathrm{mL}$ pepstatin, $2 \mathrm{mmol} / \mathrm{L}$ phenylmethylsulfonyl fluoride, $4 \mathrm{mmol} / \mathrm{L}$ ethylenediamine tetraacetic acid, $0.5 \mathrm{mmol} / \mathrm{L}$ zinc chloride, and $1 \mathrm{mmol} / \mathrm{L}$ sodium orthovanadate (stop buffer). The cells were washed once in stop buffer and then lysed in Laemmli sample buffer. The samples were then boiled for 5 minutes and centrifuged for 10 minutes at $14,000 \mathrm{~g}$. The samples were then electrophoresed under reducing conditions in a $4 \%$ to $20 \%$ gradient sodium dodecylsulfate-polyacrylamide gel electrophoresis. The gel was transferred to a nitrocellulose membrane and blocked in TRIS-buffered saline containing $0.5 \%$ Tween-20 and $5 \%$ bovine serum albumin for 1 hour. The membranes were then immunoblotted with the PY20 antiphosphotyrosine monoclonal antibody (1:1000) (Transduction Laboratories, Lexington, Ky) or the MOPC monoclonal antibody as isotype control (ICN Pharmaceuticals, Costa Mesa, Calif) for 1 hour. The membranes were then washed ( $3 \times)$ and blocked in TRISbuffered saline containing $0.5 \%$ Tween- 20 and $5 \%$ nonfat dry milk. After 1 hour, the membranes were incubated with horseradish peroxidase-conjugated goat anti-mouse IgG (1:5000; Organon Teknika, Durham, NC) for 1 hour. The membranes were then washed $(3 \times)$, and the reaction was visualized by using the ECL Western Blot detection system according to the manufacturer's instructions (Amersham, Buckinghamshire, England).

Before blocking, the nitrocellulose membranes were stained with Ponceau-S to verify equivalent protein loading in each lane. The membranes immunoblotted with the MOPC monoclonal antibody were developed in an identical manner as the membranes immunoblotted with the PY-20 monoclon- 


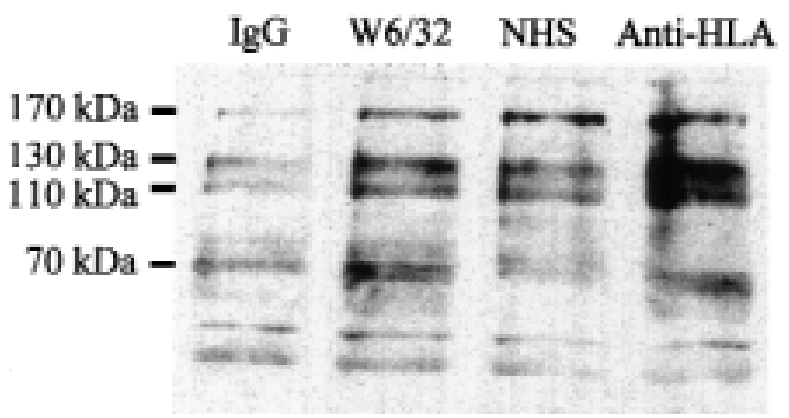

Fig 1. Induction of tyrosine phosphorylation by anti-HLA antibody binding. A549 cells were incubated for 5 minutes in the presence of control mouse IgG (lane 1), W6/32 monoclonal antibody (lane 2), NHS (lane 3), and pooled anti-HLA serum (lane 4). Cell samples were then analyzed by immunoblotting with the PY20 antiphosphotyrosine monoclonal antibody. The results are representative of 2 different experiments.

al antibody. The immunoblotting with the MOPC monoclonal antibody did not reveal any specific bands in any of the samples (data not shown).

Proliferation assay. The A549 cells were seeded in 96well, flat-bottom plates at $1 \times 10^{3}$ cells per well in quadruplicate in complete medium. After 24 hours, the medium was replaced with starvation medium. After 48 hours, the cells were incubated in starvation medium containing the W6/32 anti-HLA monoclonal antibody $(10 \mu \mathrm{g} / \mathrm{mL})$, control mouse IgG $(10 \mu \mathrm{g} / \mathrm{mL})$, anti-HLA serum (1:20), NHS (1:20), or anti-HLA ${ }^{+}$and anti-HLA ${ }^{-}$sera from lung transplant recipients $(1: 20)$. Cultures incubated in complete medium were used as positive controls. The cells were then incubated for 24, 48, and 72 hours. Tritiated thymidine ( $1 \mu \mathrm{Ci} /$ well) (ICN Pharmaceuticals) was added for the last 24 hours of incubation. At the end of the incubation period, the cultures were harvested onto solid phase filters, and the tritiated thymidine uptake was measured in a Wallac Microbeta Plus scintillation counter (Wallac, Gathersburg, Md). The tritiated thymidine uptake was expressed as counts per minute.

Statistical analysis. Statistical analysis of the data was carried out by means of the Student $t$ test.

\section{Results}

Induction of tyrosine phosphorylation by antiHLA antibody binding. Western blot analysis was performed to determine whether binding of anti-HLA antibodies to the surface of the A549 airway epithelial cell line causes signal transduction mediated by tyrosine phosphorylation of intracellular proteins. Treatment of A549 cells with the W6/32 monoclonal antibody for 5 minutes induced tyrosine phosphoryla-

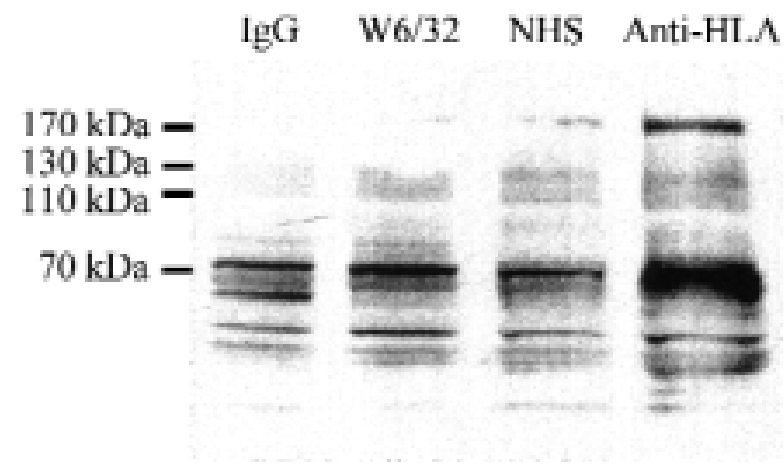

Fig 2. Induction of AEC tyrosine phosphorylation by antiHLA antibody binding. A549 cells were incubated for 10 minutes in the presence of control mouse $\operatorname{IgG}$ (lane 1), W6/32 monoclonal antibody (lane 2), NHS (lane 3), and pooled anti-HLA serum (lane 4). Cell samples were then analyzed by immunoblotting with the PY20 antiphosphotyrosine monoclonal antibody. The results are representative of 2 different experiments.

tion of proteins of approximately 170,130 , and $110 \mathrm{kd}$ when compared with the cells treated with control mouse IgG (Fig 1). There is also a small increase in the phosphorylation of a protein of approximately $70 \mathrm{kd}$ (Fig 1). After 10 minutes, binding of the W6/32 monoclonal antibody induced increased phosphorylation of the same 70-kd protein (Fig 2). The 130- and 110-kd proteins were no longer phosphorylated, and the 170$\mathrm{kd}$ protein is substantially less tyrosine phosphorylated compared with that undergoing the 5-minute treatment (Fig 2). Increased tyrosine phosphorylation was not detected in cells treated with the control mouse $\operatorname{IgG}$ compared with cells treated with starvation medium alone (data not shown).

Treatment of A549 cells with the pooled anti-HLA serum for 5 minutes also resulted in increased tyrosine phosphorylation of proteins of approximately 170, 130, 110 , and $70 \mathrm{kd}$ when compared with cells treated with NHS (Fig 1). After 10 minutes, the 170-kd protein remains highly phosphorylated, and the $70-\mathrm{kd}$ protein shows a marked increase in tyrosine phosphorylation (Fig 2). Increased tyrosine phosphorylation was not detected in cells treated with NHS compared with cells treated with starvation medium alone (data not shown).

Induction of proliferation by anti-HLA antibody binding. The tritiated thymidine uptake of A549 cells treated with the W6/32 monoclonal antibody resulted in a markedly increased uptake when compared with cells treated with the control mouse $\operatorname{IgG}(P=.006, P=$ .0008 , and $P=.01$ on days 1,2 , and 3 , respectively) (Fig 3). On day 2, a significant difference of tritiated 


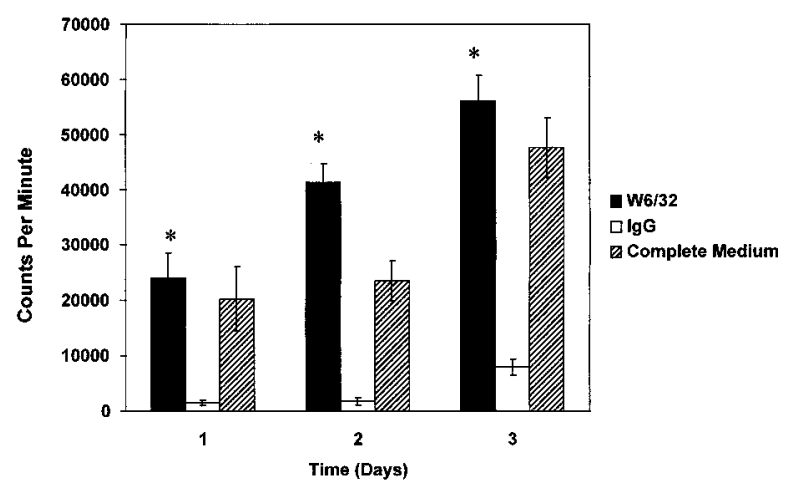

Fig 3. Stimulation of AEC proliferation by the W6/32 monoclonal antibody. A549 cells were starved for 48 hours and then incubated in the presence of the W6/32 monoclonal antibody, control mouse IgG (negative control), or complete medium (positive control) for 24,48 , and 72 hours. Cell proliferation was determined by tritiated thymidine incorporation. The results of quadruplicate cultures $(n=4)$ are expressed as the mean values \pm SD and are representative of 3 different experiments. $* P<.05$.

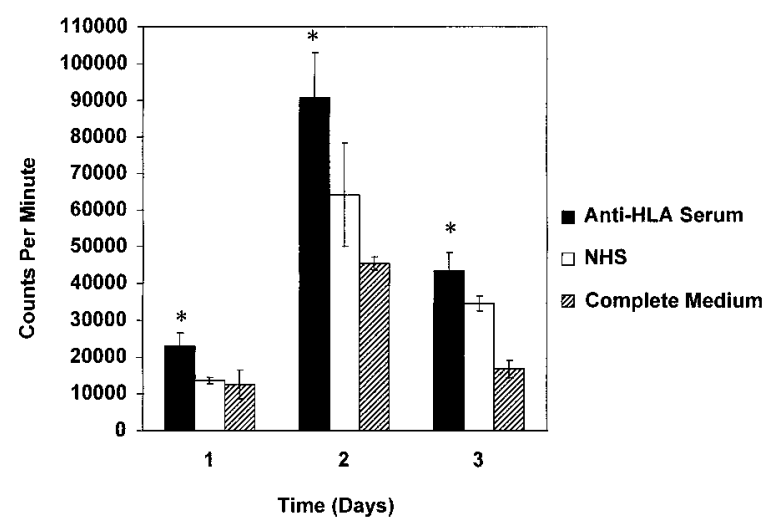

Fig 4. Stimulation of AEC proliferation by the pooled antiHLA serum. A549 cells were starved for 48 hours and then incubated in the presence of the pooled anti-HLA serum, NHS (negative control), or complete medium (positive control) for 24, 48, and 72 hours. Cell proliferation was determined by tritiated thymidine incorporation. The results of quadruplicate cultures $(n=4)$ are expressed as the mean values \pm SD and are representative of 3 different experiments. $* P<.05$.

thymidine uptake was observed between cells treated with the W6/32 monoclonal antibody and cells treated with complete medium $(P=.001)$ (Fig 3).

To determine whether serum from patients sensitized against the HLA molecule would induce similar proliferation in the AECs, we incubated these A549 cells with the pooled anti-HLA serum from 10 patients with high reactivity against the HLA molecule. This treat-

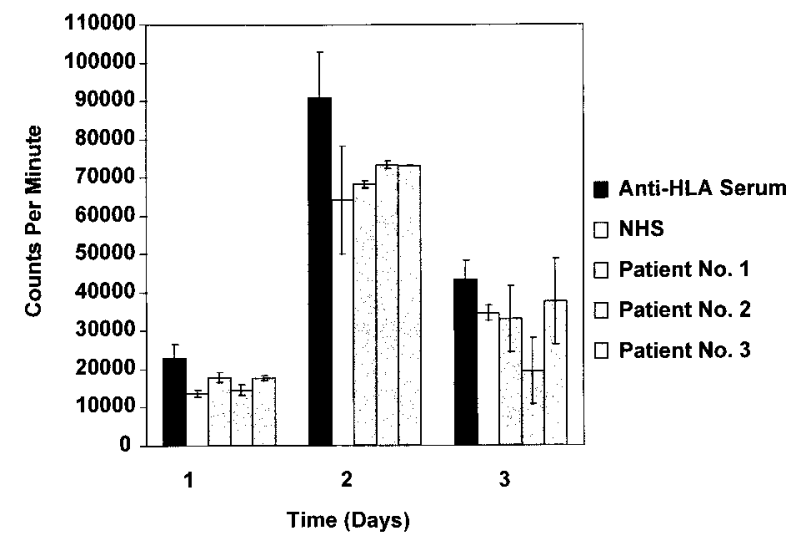

Fig 5. Stimulation of AEC proliferation by anti-HLA ${ }^{+}$sera from lung transplant recipients with BOS at the time of the study. A549 cells were starved for 48 hours and then incubated in the presence of anti-HLA ${ }^{+}$sera from lung transplant recipients with BOS at the time of the study, pooled antiHLA serum (positive control), or NHS (negative control) for 24,48 , and 72 hours. Cell proliferation was determined by tritiated thymidine incorporation. The results of quadruplicate cultures $(n=4)$ are expressed as the mean values $\pm S D$ and are representative of 3 different experiments.

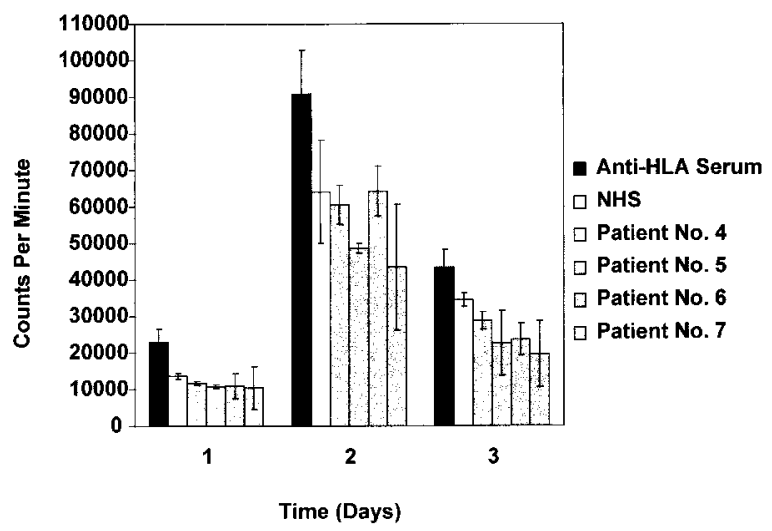

Fig 6. Lack of stimulation of AEC proliferation by anti-HLA ${ }^{-}$ sera from lung transplant recipients without BOS at the time of the study. A549 cells were starved for 48 hours and then incubated in the presence of anti-HLA ${ }^{-}$sera from lung transplant recipients without BOS at the time of the study, pooled anti-HLA serum, or NHS for 24,48 , and 72 hours. Cell proliferation was determined by tritiated thymidine incorporation. The results of quadruplicate cultures $(n=4)$ are expressed as the mean values \pm SD and are representative of 3 different experiments.

ment induced a significantly increased tritiated thymidine uptake when compared with cells treated with NHS $(P=.005, P=.01$, and $P=.01$ on days 1,2 , and 3 , respectively). In fact, the addition of the pooled antiHLA serum had greater proliferative capability when 
compared with complete medium $(P=.003, P=.002$, and $P=.0002$ on days 1,2 , and 3, respectively) (Fig 4 ). The maximum effect of both the W6/32 monoclonal antibody and the pooled anti-HLA serum occurred on day 2 (Figs 3 and 4).

More significantly, posttransplant serum from lung allograft recipients who were either anti-HLA ${ }^{+}$or anti$\mathrm{HLA}^{-}$also had similar effects. Anti-HLA ${ }^{+}$sera from lung transplant recipients with BOS at the time of the study induced an increased tritiated thymidine uptake when compared with NHS, but the difference did not reach statistical significance $(P=.1, P=.2$, and $P=.2$ on days 1,2 , and 3 , respectively) (Fig 5). It is noteworthy that these patients were sensitized only by the donor HLA, whereas the individuals who contributed to the pooled anti-HLA serum were sensitized by multiple blood transfusions and were not receiving an immunosuppression regimen at the time of the blood collection. Hence lung transplant recipient sera had a decreased antibody concentration that was donor HLA specific. On the contrary, anti-HLA ${ }^{-}$sera from lung transplant recipients without BOS at the time of the study induced tritiated thymidine uptake comparable with that of NHS (Fig 6). Comparison of the anti-HLA ${ }^{+}$ lung transplant recipient group with the anti-HLA ${ }^{-}$ lung transplant recipient group revealed statistically significant differences on days 1 and $2(P=.006$ and $P$ $=.00002$, respectively) .

\section{Discussion}

Chronic rejection, which is responsible for the majority of late graft failures, is defined as progressive functional deterioration of the transplanted organ occurring months or years after engraftment. It is associated with vascular obliteration and other architectural changes that lead to a gradual fibrosis. ${ }^{10}$ The target of the immune response to lung allografts has not been definitively determined. In both renal and cardiac allografts the vascular endothelium appears to be intimately involved in chronic rejection. However, the epithelium of both kidney and liver allografts also appears to be involved. In renal and hepatic transplantation, one manifestation of chronic rejection is the disappearance of the renal tubules and the bile ducts, both of which are lined by epithelium. 3,11,12 Several studies have implicated the bronchial epithelium as the target for the chronic rejection process after lung transplantation, a role not unlike the one played by the vascular endothelium in cardiac and renal allografts. ${ }^{13,14}$

The expression of major histocompatibility complex (MHC) class II antigens on the bronchial epithelium has been postulated to be the stimulus for BOS. ${ }^{15}$ AECs constitutively express HLA class I and are capable of
HLA class II expression in the setting of inflammation or immunologic activation. ${ }^{16,17}$ In a rat model both MHC class I and II molecules are upregulated in rejecting lung allografts. ${ }^{14,18}$ BET-1A, a human AEC line, upregulates the expression of intercellular adhesion molecule 1 and both MHC class I and II antigens after exposure to interferon- $\gamma \cdot{ }^{13}$ AECs do not present antigen in the context of HLA as efficiently as pulmonary macrophages, but they have been reported to augment the antigen presenting function of macrophages. ${ }^{19}$ In addition, an increased number of dendritic cells are associated with the bronchial epithelium in rejecting allografts. ${ }^{4}$ Because dendritic cells are among the most efficient antigen presenting cells, this increased population of dendritic cells would compensate for poor antigen presentation by the bronchial epithelium.

HLA antigens are suspected to be the major stimulus for chronic rejection because recipients with mismatch at both the HLA class I and II loci have decreased graft survival. ${ }^{20}$ The expression of MHC class II antigens on the bronchial epithelium has been postulated to be the major stimulus for BOS. ${ }^{15}$ However, allografts with mismatches only at the HLA class I loci can stimulate a complete $\mathrm{T}$ cell-dependent immune response. ${ }^{21}$ Mismatched HLA class I peptides have been shown to be recognized by the recipient $\mathrm{CD}^{+} \mathrm{T}$ cell through the indirect pathway. ${ }^{22}$ In fact, reactivity against mismatched HLA class I antigens carries a worse prognosis for lung transplant recipients. ${ }^{23-25}$ HLA class II-reactive lymphocytes are reported to be associated with steroidresponsive BOS, whereas HLA class I-reactive lymphocytes are associated with a treatment-resistant course. ${ }^{23-25} \mathrm{CD}^{+} \mathrm{T}$ cells that recognize HLA class I mismatches through the indirect pathway can contribute to allograft rejection by providing the cytokines necessary for stimulation of B cells, resulting in a specific anti-HLA class I humoral immune response. ${ }^{21,22}$

Chronic rejection in many experimental models and clinical scenarios is associated with the development of anti-HLA antibodies. ${ }^{9}$ Antibody-mediated rejection has been reported in both heart and kidney allografts. ${ }^{26}$ Recent studies in the rat model have noted the potential role of $\mathrm{T}$ cell-dependent humoral immune response in MHC class I-disparate allograft rejection. ${ }^{27} \mathrm{HLA}$ class I mismatch and the development of anti-HLA antibodies have been linked with early onset of BOS. ${ }^{6,7}$ The results presented in this study (Figs 1 and 2), as well as those in a report by Bian and colleagues ${ }^{9}$ indicate that signal transduction involving tyrosine phosphorylation may play a vital role in epithelial cell activation by anti-HLA antibodies. Furthermore, anti-HLA antibody binding to AECs also induces intracellular calcium influx in AECs (unpublished observations, May 1999). 
Although HLA class I molecules are not associated with $\mathrm{G}$ proteins and do not have tyrosine kinase activity, MHC class I molecules have been shown to be able to transduce intracellular signals, which can result in cellular proliferation. ${ }^{28-30}$

We have shown herein that anti-HLA antibody binding to AECs induces proliferation in the near absence of growth factors present in the starvation media. This suggests that the signaling pathway activated by the anti-HLA antibodies may induce the production of growth factors or may allow the cells to use the available growth factors more efficiently. In this regard, Harris and colleagues ${ }^{10}$ have recently reported that endothelial cells upregulate the expression of fibroblast growth factor receptor when treated with the W6/32 monoclonal antibody.

Treatment with pooled anti-HLA serum had a greater proliferative effect than treatment with the W6/32 monoclonal antibody. The polyvalent nature of the anti-HLA antibodies in the pooled anti-HLA serum is the most plausible explanation for this effect. In addition, the intrinsic growth factors present in human serum may also explain the increased proliferation of A549 cells when treated with NHS compared with complete medium (Fig 4).

More significantly, anti-HLA antibodies that developed after lung transplantation also induced increased proliferation of AECs but not at the same level as the highly reactive pooled anti-HLA serum (Fig 5). In contrast, the anti-HLA ${ }^{-}$sera from lung transplant recipients without BOS at the time of the study induced proliferation comparable with that of NHS (Fig 6). This indicates that the proliferative effect induced by the anti-HLA ${ }^{+}$sera from lung transplant recipients with BOS at the time of the study is due to the direct effect of the anti-HLA antibodies and not a result of the immunosuppressive agents, such as corticosteroids, which can act as growth factors in culture.

In summary, the data presented in this study show that anti-HLA antibodies bind to AECs and stimulate tyrosine phosphorylation of intracellular proteins. The ligation of the MHC class I molecules transduces an intracellular signal, which ultimately results in increased proliferation of the A549 cells in the absence of growth factors. The pathway that leads from signal transduction at the cell membrane to cellular proliferation is yet to be elucidated. It has been shown that AECs can produce mesenchymal growth factors. ${ }^{13}$ These growth factors could act in an autocrine and a paracrine fashion to stimulate the proliferation of AECs, as well as fibroblasts and smooth muscle cells, which could ultimately result in the tissue remodeling observed in obliterative bronchiolitis developed after lung transplantation. Current studies in our laboratory are focused on determining whether binding of antiHLA antibodies to AECs also induces an increased production of fibrogenic growth factors. The identification of a growth factor or factors for fibroblasts and smooth muscle cells produced by AECs and upregulated by anti-HLA antibody binding may allow for early intervention and successful treatment of BOS before any significant lesions develop in the bronchi, leading to reduction of pulmonary function in lung transplant recipients.

\section{REFERENCES}

1. Reichenspurner H, Girgis R, Robbins R, Conte J, Nair R, Valentine $\mathrm{V}$, et al. Obliteratative bronchiolitis after lung and heart-lung transplantation. Ann Thorac Surg 1995;60:1845-53.

2. Hino K, Grogan JB, Hardy JD. Viability of stored lungs. Transplantation 1968;6:25-32.

3. Paradis I. Bronchiolitis obliterans: pathogenesis, prevention and management. Am J Med Sci 1998;315:161-78.

4. Tilney NL, Whitley WD, Diamond JR, Kupiec-Weglinski JW, Adams DH. Chronic rejection-an undefined conundrum. Transplantation 1991;52:389-98.

5. Fenoglio J, Ho E, Reed E, Rose E, Smith C, Reemstma K, et al. Anti-HLA antibodies and heart allograft survival. Transplant Proc 1989;21:807-09.

6. Smith MA, Sundaresan S, Mohanakumar T, Trulock EP, Lynch J, Phelan D, et al. Effect of development of antibodies to HLA and cytomegalovirus mismatch on lung transplantation and development of bronchiolitis obliterans syndrome. J Thorac Cardiovasc Surg 1998;116:812-20.

7. Sundaresan S, Mohanakumar T, Smith MA, Trulock EP, Lynch J, Phelan D, et al. HLA-A locus mismatches and development of antibodies to HLA after lung transplantation correlate with the development of bronchiolitis obliterans syndrome. Transplantation 1998;65:648-53.

8. Novick RJ, Bennett LE, Quantz M. Influence of HLA matching on survival and development of obliterative bronchiolitis (OB) after lung transplantation. J Heart Lung Transplant 1999;18:50-1

9. Bian H, Harris P, Mulder A. Reed E. Anti-HLA antibody ligation to HLA Class I molecules expressed by endothelial cells stimulates tyrosine phosphorylation, inositol phosphate generation, and proliferation. Hum Immunol 1997;53:90-7.

10. Harris PE, Bian H, Reed E. Induction of high affinity fibroblast growth factor receptor expression and proliferation in human endothelial cells by anti-HLA antibodies: a possible mechanism for Transplant Atherosclerosis. J. Immunol 1997;159:5697-704.

11. Randhawa PS, Shapiro R, Jordan MI, Starzl TE, Demetris AJ. The histopathological changes associated with allograft rejection and drug toxicity in renal transplant recipients maintained on FK506. Clinical significance and comparison with cyclosporine. Am J Surg Path 1993;17:60-8.

12. Oguma S, Belle S, Starzl TE, Demetris AJ. A histometric analysis of chronically rejected human liver allografts: insights into the mechansims of bile duct loss: direct immunologic and ischemic factors. Hepatology 1989;9:204-9.

13. Mauck KA, Hosenpud, JD. The bornchial epithelium: a potential allogeneic target for chronic rejection after lung transplantation. J Heart Lung Transplant 1996;15:709-14.

14. Kubota H, Yagyu K, Takeshita OM, Furuse A. Importance of 
bronchus-associated lymphoid tissue and major histocompatibility complex class I and class II antigen expression on bronchial epithelium in acute lung allograft rejection and lung infection in rats. Transplant Proc 1994;26:1856-8.

15. Burke CM, Glanvile AR, Theodore J, Robin ED. Lung immunogenicity, rejection and obliterative bronchiolitis Chest 1987;92: 547-9.

16. Spurzem JR, Sacco O, Rossi G, Beckmann JD, Rennard SI. Regulation of major histocompatibility complex class II gene expression on bovine bronchial epithelial cells. J Lab Clin Med 1992;120:94-102.

17. Taylor PM, Rose M, Yacoub M. Expression of MHC antigens in normal human lungs and transplanted lungs with obliterative bronchiolitis. Transplantation 1989;48:506-10.

18. Romaniuk A, Pro J, Petersen AH, Wildevuur CRH, Nieuwenhuis P. Expression of class II major histocompatibility complex antigens bronchial epithelium in rat lung allografts. Transplantation 1987;44:209-14.

19. Mezzetti M, Soloperto M, Fasoli A, Mattoli S. Human bronchial epithelial cells modulate CD3 and mitogen-induced DNA synthesis in $\mathrm{T}$ cells but function poorly as antigen-presenting cells compared to pulmonary macrophages. J Allergy Clin Immunol 1991;87:487-8

20. Thorogood J, van Houwelinge HC, van Rood JJ, Zantvoort FA, Schreuder GM, Persijn GG. Factors contributing to long-term kidney graft survival in Eurotransplant. Transplantation 1992; 52:152-8.

21. Pettigrew GJ, Lovegrove E, Bradley JA, Maclean J, Bolton E. Indirect $\mathrm{T}$ cell allorecognition and alloantibody-mediated rejection MHC class I-disparate heart grafts. J Immunol 1998;161: 1292-8.

22. Siva Sai KSR, Smith MA, Poindexter NJ, Sundaresan, SR, Trulock EP, Lynch JP, et al. Indirect recognition of donor HLA class I peptides in lung transplant recipients with bronchiolitis obliterans syndrome. Transplantation 1999;67:1094-8

23. Reinsmoen NL, Bolman RM, Savik K, Butters K, Hertz M. Differentiation of class I- and class II-directed donor-specific alloreactivity in bronchoalveolar lavage lymphocytes from lung transplant recipients. Transplantation 1992;53:181-9.

24. Zeevi A, Rabinowich SA, Paradis IL, Dauber JD, Kormos R, Armitage J, et al. Presence of donor-specific alloreactivity in histologically normal lung allografts is predictive of subsequent bronchiolitis obliterans. Transplant Proc 1991;23:1128-9.

25. Reinsmoen NL, Bolman RM, Savik K, Butters K, Hertz MI. Are multiple immunopathogenetic events occurring during the development of obliterative bronchiolitis and acute rejection? Transplantation 1993;55:1040-4.

26. Halloran PF, Schlaut J, Solez K, Srinivasa NS. The significance of anti-class 1 response: clinical and pathologic features of renal transplants with anti-class 1-like antibody. Transplantation 1992; 53:50-5.

27. Morton AL, Bell EB, Bolton E, Marshall HE, Roadknight C, McDonagh $\mathrm{M}$, et al. CD4+ T cell-mediated rejection of major histocompatibility complex class I-disparate grafts: a role for alloantibody. Eur J Immunol 1993;23:2078-84.

28. Bregenholt S, Ropke M, Skov S, Claesson MH. Ligation of MHC class I molecules on peripheral blood T lymphocytes induces new phenotypes and functions. J Immunol 1996;157:993-9.

29. Schrieber AB, Schlessinger J, Edidin M. Interaction between major histocompatibility complex antigens and epidermal growth factor receptors on human cells. J Cell Biol 1984;98:725-31.

30. Geppert TD, Wacholtz MC, Patel SS, Lightfoot E, Lipsky PE Activation of human $\mathrm{T}$ cell clones and Jurkat cells by cross-linking class I MHC molecules. J Immunol 1989;142:3763-72.

\section{Discussion}

Dr Dao M. Nguyen (Bethesda, Md). I have one question. You showed that the P170 protein band has the tyrosine phosphorylation. Did you have a chance to characterize that protein? Is that an epidermal growth factor receptor?

Dr Reznik. That is one of the possibilities. These studies are very preliminary. We have some postulated identities for various hyperphosphorylated bands, and the epidermal growth factor receptor is one of the possibilities for the 170kd band.

Dr Nguyen. Are you planning to use a tyrosine kinase inhibitor to determine whether you can downregulate this pathway?

Dr Reznik. We are currently working on it.

Dr Valerie W. Rusch (New York, NY). Why did you use the A549 cell line and why is that relevant to a lung transplant model?

Dr Reznik. We used A549 in our pilot studies to work out this experimental system. A549 has been used by many investigators studying the biology of the lung epithelium. However, we also have preliminary data obtained with primary bronchial epithelial cell lines that we developed from our lung donors, and we have similar results, including the tyrosine phosphorylation assays. The primary epithelial cell lines grow very slowly so that it is difficult to measure differences in proliferation assays.

Dr Rusch. Are those short-term cultures that you have established?

Dr Reznik. We use both primary cell cultures and SV40 transformed cell lines, because the primary airway epithelial lines only last 4 or 5 passages.

Dr Rusch. I wonder about this because this is a bronchoalveolar or adenocarcinoma cell line, which may not be relevant to a benign lung model.

Dr Reznik. A549 is derived from a lung epithelial carcinoma. We are, however, also concerned about the differences between transformed cells and benign lung epithelial cells. As I mentioned, the salient points of our results were confirmed by using primary cell lines.

Dr Scott J. Swanson (Boston, Mass). Have you been able to demonstrate a correlation between HLA mismatching and the development of BOS in your clinical trials?

Dr Reznik. Our group has recently reported the outcome of lung transplant recipients who are having mismatches at the HLA-A locus (Sundaresan et al. Transplantation 1998;65:648-53). Furthermore, we have shown that production of antibodies against HLA correlates with the development of BOS (Smith et al. J Thorac Cardiovasc Surg 1998; 116:812-20; Jaramillo et al. Transplant Proc 1999;31:185-6). 